\title{
FAKTOR-FAKTOR YANG MEMPENGARUHI HARGA CABAI RAWIT DI PASAR NGABLAK, KABUPATEN MAGELANG
}

\author{
*Fina, Yuliawati \\ Program Studi Agribisnis Fakultas Pertanian dan Bisnis, Universitas Kristen Satya \\ Wacana, Salatiga \\ *Corresponding email: 522013008@ student.uksw.edu
}

\begin{abstract}
The aim of this study is to find out about the effect of distribution channel, substitution commodity price and consumer demand for cayenne pepper price in Ngablak Market, District of Magelang, Central Java. The sampling method used in this study was simple random sampling, in which 36 respondents were used. The type of this study is a descriptive quantitative. This study used a survey as the method by interviewing respondents in a research location. Data analysis used in this study was multiple linear regression. The result of this study shows that distribution channel and curly red chili price have real effect on cayenne pepper price on the other hand, consumer demand for cayenne pepper didn't have any real effect on cayenne pepper price.
\end{abstract}

Keywords: price, cayenne pepper, distribution channel, demand.

\begin{abstract}
Abstrak: Penelitian ini bertujuan untuk mengetahui pengaruh dari faktor saluran distribusi, harga komoditas pengganti (substitusi) dan permintaan konsumen terhadap harga cabai rawit di Pasar Ngablak, Kabupaten Magelang, Jawa Tengah. Pengambilan sampel dilakukan dengan teknik simple random sampling dan didapatkan sampel sebanyak 36 responden. Jenis penelitian yang digunakan adalah penelitian deskriptif kuantitatif. Metode penelitian yang digunakan adalah metode survey dengan cara mewawancarai responden di lokasi penelitian. Analisis data yang digunakan dalam penelitian ini yaitu regresi linear berganda. Hasil penelitian menunjukkan bahwa variabel saluran distribusi dan harga cabai merah keriting berpengaruhnyata terhadap harga cabai rawit sementara permintaan konsumen terhadap cabai rawit tidak berpengaruhnyata terhadap harga cabai rawit.
\end{abstract}

Kata Kunci: harga, cabai rawit, saluran distribusi, permintaan.

\section{PENDAHULUAN}

Cabai rawit (Capsicum frutescens L.) termasuk salah satu komoditas sayuran yang mempunyai nilai ekonomi cukup tinggi karena mayoritas masyarakat Indonesia menyukai makanan bercita rasa pedas. Masyarakat Indonesia memanfaatkan cabai rawit sebagai bahan baku bumbu masakan, sehingga keberadaan cabai rawit dapat memberikan prospek usaha yang cerah untuk meningkatkan pertumbuhan ekonomi di sektor pertanian.

Badan Pusat Statistik (2015) menyatakan bahwa cabai rawit termasuk komoditas
Subsektor Tanaman Hortikultura kelompok sayur-sayuran yang harganya sangat fluktuatif. Menurut Simatupang (1999, lihat Irawan, 2007) fluktuasi harga seringkali merugikan petani dibandingkan pedagang karena petani umumnya tidak dapat mengatur waktu penjualannya untuk mendapatkan harga jual yang lebih menguntungkan.

Menurut Prastowo et al. (2011) harga komoditas yang terbentuk pada tingkat akhir atau konsumen sangat tergantung pada panjang pendeknya saluran distribusi. Semakin panjang saluran distribusinya maka harga komoditas semakin meningkat begitupun sebaliknya. Pada 


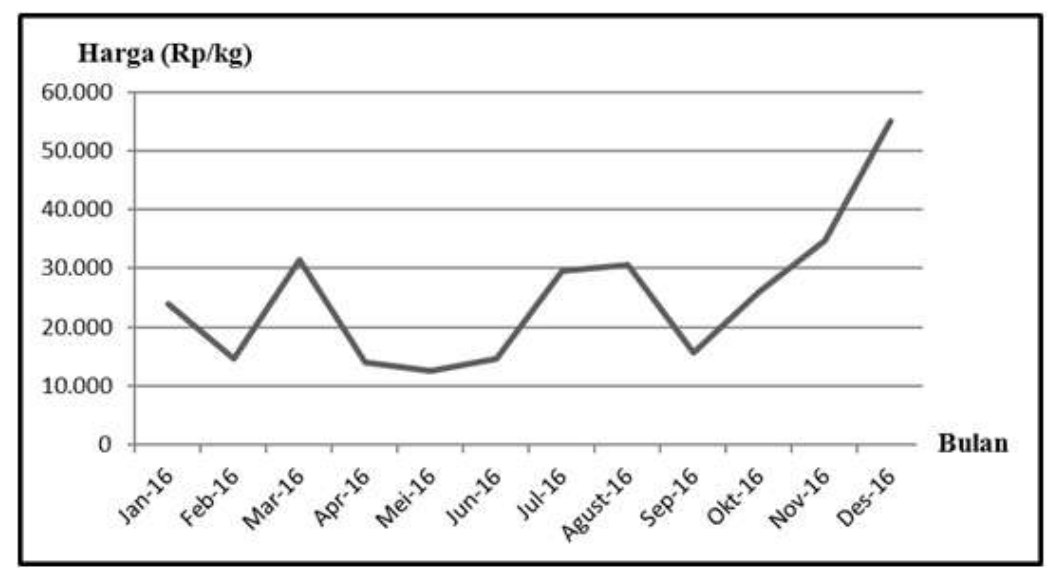

Gambar 1. Perkembangan harga produsen cabai rawit di kabupaten Magelang berdasarkan data bulanan periode Januari-Desember 2016 (Sumber: Direktorat Jendral Hortikultura, 2016)

penelitian Palar et al. (2016) salah satu faktor yang mempengaruhi harga cabai yaitu harga komoditas pengganti (substitusi). Komoditas pengganti adalah komoditas yang dapat menggantikan fungsi komoditas lain sehingga harga komoditas pengganti dapat mempengaruhi permintaan komoditas yang dapat digantikannya (Sugiarto, 2000; Palar et al., 2016). Apabila harga komoditas utama meningkat maka penjual akan meningkatkan jumlah komoditas pengganti yang ditawarkan. Penjual berharap, konsumen akan beralih dari komoditas utama ke komoditas pengganti yang ditawarkan, karena harganya lebih rendah (Palar et al., 2016).Selain itu, permintaan juga mempengaruhi harga cabai rawit, yang dimaksud permintaan adalah jumlah cabai rawit yang diminta konsumen pada berbagai tingkat harga pada waktu tertentu (Sudarsono, 1985).

Menurut Badan Pusat Statistik (2015) Kabupaten Magelang termasuk salah satu sentra cabai rawit dengan produksi 68.208 kuintal yang menempati urutan ke-8 dari 29 kabupaten di Jawa Tengah. Adapun perkembangan harga cabai rawit di Kabupaten Magelang yang berfluktuasi tiap bulannya disajikan pada Gambar 1.

Dari Gambar 1 dapat dilihat bahwa harga cabai rawit tertinggi berdasarkan data bulanan terdapat pada bulan Desember yaitu pada tingkat harga Rp. $55.000 \mathrm{~kg}^{-1}$, sedangkan harga terendah terdapat pada bulan Mei yaitu pada tingkat harga Rp. $12.475 \mathrm{~kg}^{-1}$. Perbedaan nilai harga tertinggi dan harga terendah adalah $\mathrm{Rp}$.
$42.525 \mathrm{~kg}^{-1}$ atau sebesar $340,8 \%$ dari harga terendah.

Penelitian ini bertujuan untuk mengetahui pengaruh dari faktor saluran distribusi, harga komoditas pengganti (substitusi) dan permintaan konsumen terhadap harga cabai rawit di Pasar Ngablak, Kabupaten Magelang, Jawa Tengah.

\section{METODE PENELITIAN}

Penelitian ini dilaksanakan pada bulan April 2017 sampai bulan Mei 2017 berlokasi di Pasar Ngablak, Kabupaten Magelang, Jawa Tengah. Pemilihan lokasi ini dilakukan secara sengaja (puRp.osive) karena pasar Ngablak terletak di Kecamatan Ngablak yang merupakan salah satu daerah penghasil tanaman hortikultura di Kabupaten Magelang. Berdasarkan data BPS Kabupaten Magelang (2016), 17\% dari luas wilayah di Kecamatan Ngablak digunakan untuk tanaman hortikultura cabai rawit dan cabai merah keriting, serta hasil panennya dijual ke pasar Ngablak. Selain itu, pasar Ngablak sebagai pusat distribusi dan pemasaran cabai rawit ke Salatiga, Ampel dan Tegalrejo.

Pengambilan sampel dalam penelitian ini menggunakan simple random sampling. Populasi dalam penelitian ini berjumlah 40 orang pedagang sayuran yang menjual cabai rawit dan cabai merah keriting, untuk menentukan sampel dari banyaknya populasi maka digunakan teknik Solvin sehingga didapatkan 36 sampel pedagang. 
Pengumpulan data dilakukan dengan metode survei. Data yang dikumpulkan berupa data primer dan sekunder. Data primer dalam penelitian ini diperoleh melalui observasi, dokumentasi dan wawancara langsung menggunakan kuesioner kepada pedagang cabai rawit dan cabai merah keriting. Data sekunder diperoleh dari studi literatur pada buku, internet, jurnal, skripsi dan catatan atau dokumen dari instansi-instansi atau lembagalembaga terkait seperti kantor pasar, Dinas Perdagangan Koperasi dan UKM.

Data yang diperoleh kemudian dianalisis dengan analisis regresi linear berganda dengan persamaan sebagai berikut:

$$
\mathrm{Y}=\alpha+\beta_{1} \text { Dummy }+\beta_{2} \mathrm{X}_{2}+\beta_{3} \mathrm{X}_{3}+\varepsilon
$$

\section{Keterangan:}

Y : Harga Cabai Rawit (ribuan rupiah)

$\alpha \quad$ : Nilai konstanta

$\beta_{1}, \beta_{2}, \beta_{3}$ : Koefisien regresi

Dummy : Saluran Distribusi ( $0=$ langsung; $1=$ tidak langsung)

$\begin{array}{rlr}\mathrm{X}_{2} & : \text { Harga Komoditas Pengganti } \\ & \text { /Substitusi (dalam ribuan rupiah) } \\ \mathrm{X}_{3} & : \text { Permintaan Konsumen Terhadap } \\ & \text { Cabai Rawit }(\mathrm{Kg}) \\ \varepsilon & : \text { error-term }\end{array}$

\section{HASIL DAN PEMBAHASAN}

\section{Karakteristik Responden}

Karakteristik responden yang akan dibahas dalam penelitian ini yaitu dari segi usia, pendidikan dan lama berdagang.

1. Usia

Karakteristik responden berdasarkan usia disajikan pada Tabel 1.

$\underline{\text { Tabel 1. Karakteristik Responden Berdasarkan Usia }}$

\begin{tabular}{ccc}
\hline Usia (Tahun) & $\begin{array}{c}\text { Jumlah } \\
\text { Responden } \\
\text { (Orang) }\end{array}$ & $\begin{array}{c}\text { Persentase } \\
(\%)\end{array}$ \\
\hline $30-35$ & 4 & 11,1 \\
$36-41$ & 8 & 22,2 \\
$42-47$ & 6 & 16,7 \\
$48-53$ & 7 & 19,4 \\
$54-59$ & 9 & 25,0 \\
$60-65$ & 2 & 5,6 \\
\hline Jumlah & 36 & 100,0 \\
\hline Rata-Rata Usia (Tahun) & 47 \\
\hline
\end{tabular}

Sumber : Data Primer, 2017
Pembagian golongan umur responden pada penelitian ini dikelompokkan ke dalam 6 kelompok umur. Menurut BPS usia responden dapat digolongkan menjadi 3 kelompok usia yaitu belum produktif (0-14 tahun), usia produktif (15-59 tahun) dan usia non produktif (60 tahun ke atas). Diketahui pada Tabel 1. responden yang memiliki usia antara 54-59 tahun menempati persentase terbanyak yaitu sebesar 25,0\% sedangkan usia 60-65 tahun menempati persentase paling sedikit yaitu $5,6 \%$. Rata-rata usia responden yaitu 47 tahun. Responden yang memiliki usia produktif sebanyak 34 orang sedangkan usia non produktif sebanyak 2 orang.

2. Pendidikan

Karakteristik responden berdasarkan tingkat pendidikan disajikan pada Tabel 2.

Tabel 2. Karakteristik Responden Berdasarkan Pendidikan

\begin{tabular}{ccc}
\hline Pendidikan & $\begin{array}{c}\text { Jumlah } \\
\text { Responden } \\
\text { (Orang) }\end{array}$ & Persentase (\%) \\
\hline SD & 27 & 75,0 \\
SMP & 8 & 22,2 \\
SMA & 1 & 2,8 \\
\hline Jumlah & 36 & 100,0 \\
\hline
\end{tabular}

Sumber : Data Primer, 2017

Responden yang tamat sekolah dasar (SD) merupakan responden dengan persentase terbanyak yaitu sebesar $75,0 \%$ sedangkan responden yang tamat SMA memiliki persentase paling sedikit yaitu $2,8 \%$. Tingkat pendidikan responden di Pasar Ngablak tergolong masih rendah karena sebesar 75,0\% responden hanya menempuh pendidikan sampai tingkat SD. Hal ini dikarenakan kondisi responden pada zaman dulu tidak memiliki biaya untuk melanjutkan sekolah serta jarak antara sekolah dan tempat tinggal yang masih jauh.

\section{Lama Berdagang}

Karakteristik responden berdasarkan lama berdagang disajikan pada Tabel 3. Pembagian golongan lama berdagang pada penelitian ini dikelompokkan ke dalam 6 kelompok. 
Tabel 3. Karakteristik Responden Berdasarkan Lama Berdagang

\begin{tabular}{ccc}
\hline $\begin{array}{c}\text { Lama } \\
\text { Berdagang } \\
\text { (Tahun) }\end{array}$ & $\begin{array}{c}\text { Jumlah } \\
\text { Responden } \\
(\text { Orang) }\end{array}$ & Persentase $(\%)$ \\
\hline $2-7$ & 8 & 22,2 \\
$8-13$ & 5 & 13,9 \\
$14-19$ & 5 & 13,9 \\
$20-25$ & 12 & 33,3 \\
$26-31$ & 4 & 11,1 \\
$\geq 32$ & 2 & 5,6 \\
\hline Jumlah & 36 & 100,0 \\
\hline Rata-Rata & & \\
Lama & & \\
Berdagang & & \\
(Tahun) & &
\end{tabular}

Sumber : Data Primer, 2017

Responden yang lama berdagang antara 20-25 tahun menempati persentase terbanyak yaitu sebesar $33,3 \%$, sedangkan responden yang lama berdagang $\geq 32$ tahun menempati persentase paling sedikit yaitu 5,6\%. Rata-rata lama berdagang responden yaitu 17 tahun.

\section{Analisis Deskriptif Variabel Penelitian}

1. Saluran Distribusi

Saluran distribusi dalam penelitian ini dibagi menjadi 2 yaitu saluran distribusi secara langsung (petani) dan saluran distribusi secara tidak langsung. Saluran distribusi dalam penelitian ini disajikan pada Tabel 4.

Tabel 4. Jumlah Responden Berdasarkan Jenis Saluran Distribusi

\begin{tabular}{|c|c|c|c|}
\hline $\begin{array}{c}\text { Jenis } \\
\text { Saluran } \\
\text { Distribusi }\end{array}$ & $\begin{array}{c}\text { Alur } \\
\text { Saluran } \\
\text { Distribusi }\end{array}$ & $\begin{array}{c}\text { Jumlah } \\
\text { Responden } \\
\text { (Orang) }\end{array}$ & $\begin{array}{c}\text { Persentase } \\
(\%)\end{array}$ \\
\hline & $\begin{array}{l}\text { Petani- } \\
\text { Pedagang } \\
\text { Besar }\end{array}$ & 8 & 22,2 \\
\hline Langsung & $\begin{array}{l}\text { Petani- } \\
\text { Pedagang } \\
\text { Pengecer }\end{array}$ & 8 & 22,2 \\
\hline $\begin{array}{c}\text { Tidak } \\
\text { Langsung }\end{array}$ & $\begin{array}{l}\text { Petani- } \\
\text { Pedagang } \\
\text { Pengumpul } \\
\text {-Pedagang } \\
\text { Pengecer }\end{array}$ & 20 & 55,6 \\
\hline Jumlah & & 36 & 100,0 \\
\hline
\end{tabular}

Sumber : Analisis data primer, 2017
Responden yang membeli cabai rawit secara tidak langsung menempati persentase terbanyak yaitu sebesar $55,6 \%$, sedangkan responden yang membeli cabai rawit secara langsung (petani) menempati persentase paling sedikit yaitu sebesar $44,4 \%$. Kriteria pedagang besar dalam penelitian ini yaitu pedagang yang membeli cabai rawit dengan jumlah $>50 \mathrm{~kg}$ kemudian dijual ke pedagang pengecer sedangkan kriteria pedagang pengecer yaitu pedagang yang membeli cabai rawit dengan jumlah $<50 \mathrm{~kg}$ kemudian dijual ke konsumen. Jumlah pedagang besar dalam penelitian ini yaitu 8 orang dan pedagang pengecer 28 orang.

2. Harga Komoditas Pengganti (Substitusi) Harga komoditas pengganti dalam penelitian ini adalah harga cabai merah keriting. Harga cabai merah keriting dalam penelitian ini disajikan pada Tabel 5.

Tabel 5. Jumlah Responden Berdasarkan Harga Cabai Merah Keriting

\begin{tabular}{ccc}
\hline $\begin{array}{c}\text { Harga Cabai Merah } \\
\text { Keriting (Rp.) }\end{array}$ & $\begin{array}{c}\text { Jumlah } \\
\text { Responden } \\
\text { (Orang) }\end{array}$ & $\begin{array}{c}\text { Persentase } \\
(\%)\end{array}$ \\
\hline $11.000-14.096$ & 13 & 36,0 \\
$14.097-17.193$ & 9 & 25,0 \\
$17.194-20.290$ & 6 & 16,7 \\
$20.291-23.387$ & 1 & 2,8 \\
$23.388-26.484$ & 1 & 2,8 \\
$\geq 26.485$ & 6 & 16,7 \\
\hline Jumlah & 36 & 100,0 \\
\hline Rata-Rata Harga & \multicolumn{3}{c}{17.722} \\
Cabai Merah & \multicolumn{2}{|}{} \\
Keriting (Rp.) &
\end{tabular}

Sumber : Analisis data primer, 2017

Responden yang menjual cabai merah keriting dengan harga Rp. 11.000 - Rp. 14.096 menempati persentase terbanyak yaitu sebesar $36,0 \%$. Harga tertinggi cabai merah keriting yang dijual yaitu Rp. 30.000, sedangkan harga terendah yaitu Rp. 11.000. Rata-rata harga cabai merah keriting yaitu Rp. 17.722. Jumlah cabai merah keriting yang dijual responden bervariasi seperti dapat dilihat pada Tabel 6 . Jumlah cabai merah keriting yang dijual responden berkisar $1,50 \mathrm{~kg}-98,49 \mathrm{~kg}$ menempati persentase terbanyak yaitu sebesar $80,5 \%$. 
Tabel 6. Jumlah Responden Berdasarkan Jumlah Cabai Merah Keriting Yang Dijual

\begin{tabular}{|c|c|c|}
\hline $\begin{array}{c}\text { Jumlah Cabai } \\
\text { Merah Keriting } \\
(\mathrm{Kg})\end{array}$ & $\begin{array}{c}\text { Jumlah } \\
\text { Responden } \\
\text { (Orang) }\end{array}$ & $\begin{array}{l}\text { Persentase } \\
\quad(\%)\end{array}$ \\
\hline $1,50-98,49$ & 29 & 80,5 \\
\hline $98,50-195,49$ & 4 & 11,1 \\
\hline $195,50-292,49$ & 0 & 0 \\
\hline $292,50-389,49$ & 2 & 5,6 \\
\hline $389,50-486,49$ & 0 & 0 \\
\hline$\geq 486,50$ & 1 & 2,8 \\
\hline Jumlah & 36 & 100,0 \\
\hline \multicolumn{2}{|c|}{$\begin{array}{c}\text { Rata-Rata Jumlah Cabai Merah } \\
\text { Keriting }(\mathrm{Kg})\end{array}$} & 61,72 \\
\hline
\end{tabular}

Sumber : Data Primer, 2017

Jumlah terbanyak cabai merah keriting yang dijual yaitu $600 \mathrm{~kg}$ sedangkan paling sedikit yaitu $1,5 \mathrm{~kg}$. Rata-rata jumlah cabai merah keriting yang dijual yaitu $61,72 \mathrm{~kg}$.

\section{Permintaan Konsumen Terhadap Cabai Rawit}

Permintaan konsumen yang dimaksud dalam penelitian ini adalah jumlah cabai rawit yang dijual oleh pedagang. Permintaan konsumen terhadap cabai rawit dalam penelitian ini disajikan pada Tabel 7.

Tabel 7. Jumlah Responden Berdasarkan Permintaan Konsumen Terhadap Cabai Rawit

\begin{tabular}{ccc}
\hline $\begin{array}{c}\text { Permintaan } \\
\text { Konsumen (Kg) }\end{array}$ & $\begin{array}{c}\text { Jumlah } \\
\text { Responden } \\
\text { (Orang) }\end{array}$ & $\begin{array}{c}\text { Persentase } \\
(\%)\end{array}$ \\
\hline $1-162$ & 33 & 91,6 \\
$163-324$ & 2 & 5,6 \\
$\geq 325$ & 1 & 2,8 \\
\hline Jumlah & 36 & 100,0 \\
\hline Rata-Rata Permintaan Konsumen & 38,72 \\
\hline \multicolumn{2}{c}{$(\mathrm{Kg})$} &
\end{tabular}

Sumber : Data Primer, 2017

Jumlah cabai rawit yang dijual responden berkisar $1 \mathrm{~kg}-162 \mathrm{~kg}$ menempati persentase terbanyak yaitu sebesar 91,6\%. Jumlah terbanyak cabai rawit yang dijual yaitu $500 \mathrm{~kg}$ sedangkan paling sedikit yaitu $1 \mathrm{~kg}$.Rata-rata jumlah cabai rawit yang dijual sebanyak 38,72 $\mathrm{kg}$.
4. Harga Cabai Rawit

Harga cabai rawit dalam penelitian ini adalah harga cabai rawit di tingkat pedagang seperti dapat dilihat pada Tabel 8 .

Tabel 8. Jumlah Responden Berdasarkan Harga Cabai Rawit

\begin{tabular}{ccc}
\hline $\begin{array}{c}\text { Harga Cabai } \\
\text { Rawit (Rp.) }\end{array}$ & $\begin{array}{c}\text { Jumlah } \\
\text { Responden } \\
\text { (Orang) }\end{array}$ & $\begin{array}{c}\text { Persentase } \\
(\%)\end{array}$ \\
\hline $38.000-41.585$ & 4 & 11,1 \\
$41.586-45.171$ & 12 & 33,3 \\
$45.172-48.757$ & 4 & 11,1 \\
$48.758-52.343$ & 9 & 25,0 \\
$52.344-55.929$ & 3 & 8,4 \\
$\geq 55.930$ & 4 & 11,1 \\
\hline Jumlah & 36 & 100,0 \\
\hline Rata-Rata Harga & \multicolumn{2}{|}{} \\
Cabai Rawit \\
(Rp.)
\end{tabular}

Sumber : Data Primer, 2017

Responden yang menjual cabai rawit dengan harga Rp. 41.586 - Rp. 45.171 menempati persentase terbanyak yaitu sebesar $33,3 \%$. Harga tertinggi cabai rawit yaitu $\mathrm{Rp}$. 60.000 sedangkan harga terendah yaitu $\mathrm{Rp}$. 38.000. Rata-rata harga cabai rawit yaitu Rp. 47.917.

\section{Hasil Analisis Regresi}

Berdasarkan Tabel 9, maka persamaan regresi dapat dirumuskan sebagai berikut:

$$
\begin{aligned}
\mathrm{Y}= & 34,9644+3,4191 \text { Dummy }+0,6160 \mathrm{X}_{2}+ \\
& 0,0035 \mathrm{X}_{3}
\end{aligned}
$$

1. Nilai konstanta (c) sebesar 34,9644 menyatakan jika variabel saluran distribusi (Dummy), harga cabai merah keriting $\left(\mathrm{X}_{2}\right)$ dan permintaan konsumen terhadap cabai rawit $\left(\mathrm{X}_{3}\right)$ dianggap konstan, maka harga cabai rawit mencapai 34,9644.

2. Variabel dummy saluran distribusi memiliki hubungan positif dan signifikan artinya saluran distribusi memiliki dampak terhadap harga cabai rawit, saluran distribusi tidak langsung menyebabkan harga cabai rawit meningkat.

3. Koefisien regresi $X_{2}$ sebesar 0,6160 menyatakan bahwa setiap kenaikan Rp. 1 harga cabai merah keriting akan 
meningkatkan harga cabai rawit sebesar Rp. 0,6160 .

4. Koefisien regresi $X_{3}$ sebesar 0,0035 menyatakan bahwa setiap penambahan permintaan cabai rawit sebanyak $1 \%$ akan meningkatkan harga cabai rawit sebesar $0,0035 \%$.

\section{Hasil Uji Asumsi Klasik}

1. Uji Normalitas

Hasil uji normalitas didapatkan nilai J-B (Jarque-Bera) sebesar $0,457143<2$ dan probabilitas sebesar $0,795670>0,05$ sehingga dapat disimpulkan data berdistribusi normal.

\section{Uji Multikolinearitas}

Hasil uji multikolinearitas menunjukkan variabel Dummy, $\mathrm{X}_{2}$ dan $\mathrm{X}_{3}$ memiliki nilai VIF kurang dari 10. Hal ini berarti variabel Dummy, $\mathrm{X}_{2}$ dan $\mathrm{X}_{3}$ tidakterjadi multikolinearitas.

\section{Uji Heteroskedastisitas}

Hasil uji heteroskedastisitas menunjukkan nilai Obs*R-squared mempunyai nilai probabilitas Chi-square sebesar 0,3806 >0,05 sehingga dapat disimpulkan tidak terjadi heteroskedastisitas.

\section{Uji Autokorelasi}

Hasil uji autokorelasi menunjukkan nilai Obs*R-squared mempunyai nilai probabilitas Chi-square sebesar 0,7878>0,05 sehingga dapat disimpulkan tidak terjadi autokorelasi.

\section{Koefisien Determinasi $\left(\mathbf{R}^{2}\right)$}

Nilai $R^{2}$ dapat dilihat pada Tabel 9 yang menunjukkan bahwa pengaruh variabelvariabel independen terhadap variabel dependen adalah sebesar 0.603947 atau $60,39 \%$. Semakin mendekati $100 \%$, maka penelitian ini akan semakin baik.
Hal ini berarti $60,39 \%$ perubahan pada harga cabai rawit dapat dijelaskan oleh ketiga variabel independen yaitu saluran distribusi (Dummy), harga cabai merah keriting $\left(\mathrm{X}_{2}\right)$ dan permintaan konsumen terhadap cabai rawit $\left(\mathrm{X}_{3}\right)$, sedangkan sisanya $39,61 \%$ dijelaskan oleh variabel-variabel lain yang tidak termasuk dalam penelitian ini.

\section{Uji F ( Uji Simultan)}

Pada Tabel 9 hasil uji diperoleh nilai $F_{\text {hitung }}$ sebesar 18,79066 . NilaiF $F_{\text {tabel }}$ adalah 2,90. Nilai $F_{\text {hitung }} 18,79066>2,90 \quad F_{\text {tabel }}$ maka dapat disimpulkan Ho ditolak dan $\mathrm{H}_{1}$ diterima yang berarti saluran distribusi (Dummy), harga cabai merah keriting $\left(\mathrm{X}_{2}\right)$ dan permintaan konsumen terhadap cabai rawit $\left(\mathrm{X}_{3}\right)$ secara bersama-sama berpengaruhnyata terhadap harga cabai rawit (Y).

\section{Uji t (Uji Parsial)}

Hasil uji $\mathrm{t}_{\text {hitung }}$ menunjukkan bahwa variabel independen dummy saluran distribusi dan $\mathrm{X}_{2}$ berpengaruh terhadap $\mathrm{Y}$ sedangkan $\mathrm{X}_{3}$ tidak berpengaruh terhadap $\mathrm{Y}$ karena $\mathrm{t}_{\text {hitung }}<\mathrm{t}_{\text {tabel }}$. Nilai $t_{\text {tabel }}$ adalah 2,04.

Hasil uji t dapat dilihat pada Tabel 9 untuk setiap variabel independen, sebagai berikut:

1. Saluran distribusi (Dummy) $t_{\text {hitung }} 2,33>$ 2,04 $\mathrm{t}_{\text {tabel, }}$ maka dapat disimpulkan Ho ditolak dan $\mathrm{H}_{1}$ diterima yang berarti saluran distribusi berpengaruhnyata terhadap harga cabai rawit $(\mathrm{Y})$.

2. Harga cabai merah keriting $\left(\mathrm{X}_{2}\right) \mathrm{t}_{\text {hitung }} 5,29>$ 2,04 $\mathrm{t}_{\text {tabel}}$, maka dapat disimpulkan Ho ditolak dan $\mathrm{H}_{1}$ diterima yang berarti harga cabai merah keriting berpengaruh nyata terhadap harga cabai rawit $(\mathrm{Y})$.

Tabel 9. Hasil Analisis Faktor Faktor Yang Mempengaruhi Harga Cabai Rawit

\begin{tabular}{c|c|c}
\hline Variabel & Koefisien & Standard Error \\
\hline $\mathrm{C}$ & $34,9644 * * *$ & 2,1152 \\
Dummy Saluran Distribusi & $3,4191^{* *}$ & 1,4661 \\
$\mathrm{X}_{2}$ & $0,6160^{* * *}$ & 0,1164 \\
$\mathrm{X}_{3}$ & 0,0035 & 0,0076 \\
\hline R-squared & 0,6379 & \\
F-Stat & $18,79 * * *$ & \\
Jumlah Sampel & 36 & \\
\hline
\end{tabular}

Keterangan: $* * *$ Signifikan pada $\alpha=1 \%, * *$ Signifikan pada $\alpha=5 \%$, 
3. Permintaan konsumen terhadap cabai rawit $\left(\mathrm{X}_{3}\right) \mathrm{t}_{\text {hitung }} 0,45<2,04 \mathrm{t}_{\text {tabel }}$, maka dapat disimpulkan Ho diterima yang berarti permintaan konsumen terhadap cabai rawit tidak berpengaruhnyata terhadap harga cabai rawit (Y).

\section{Pengaruh Saluran Distribusi (Dummy) Terhadap Harga Cabai Rawit (Y)}

Pada Tabel 9. diperoleh nilait ${ }_{\text {hitung }} 2,33>2,04$ $\mathrm{t}_{\text {tabel, }}$ maka dari itu variabel saluran distribusi berpengaruhnyata terhadap harga cabai rawit. Hal ini sejalan dengan pendapat Prastowo et al., (2011) yang menyatakan "Harga komoditas cabai rawit yang terbentuk pada tingkat akhir atau konsumen sangat tergantung pada panjang pendeknya saluran distribusi. Semakin panjang saluran distribusinya maka harga komoditas semakin meningkat begitupun sebaliknya”.

Pada Tabel 4 menunjukkan bahwa responden di Pasar Ngablak sebesar 55,6\% menggunakan saluran distribusi secara tidak langsung sedangkan sisanya menggunakan saluran distribusi secara langsung. Responden yang membeli cabai rawit secara tidak langsung, menjual cabai rawit dengan harga yang sedikit lebih tinggi daripada responden yang membeli cabai rawit secara langsung. Proses jual beli cabai rawit di pasar ini sebagian besar harga ditentukan oleh penjual cabai rawit dan kebanyakan responden juga menjual cabai rawit secara langsung kepada konsumen.

\section{Pengaruh Harga Komoditas Pengganti $\left(\mathbf{X}_{2}\right)$ Terhadap Harga Cabai Rawit (Y)}

Pada Tabel 9. diperoleh $t_{\text {hitung }} 5,29>2,04 t_{\text {tabel }}$, maka dari itu variabel harga cabai merah keriting berpengaruh nyata terhadap harga cabai rawit. Suatu komoditas dikatakan sebagai komoditas pengganti apabila komoditas tersebut penggunaannya dapat menggantikan komoditas lain. Pada penelitian ini cabai merah keriting dianggap sebagai komoditas pengganti dari cabai rawit.

Hal ini sejalan dengan penelitian Palar et al., (2016) menyatakan "Apabila harga komoditas utama meningkat maka penjual akan meningkatkan jumlah komoditas pengganti yang ditawarkan. Penjual berharap, konsumen akan beralih dari komoditas utama ke komoditas pengganti yang ditawarkan, karena harganya lebih rendah".
Tabel 5 menunjukkan bahwa rata-rata harga cabai merah keriting Rp. $17.722 \mathrm{~kg}^{-1}$ dengan rata-rata jumlah yang dijual responden yaitu $61,72 \mathrm{~kg}$ dan Tabel 8 . menunjukkan ratarata harga cabai rawit Rp. $47.917 \mathrm{~kg}^{-1}$ dengan rata-rata jumlah yang dijual responden yaitu $38,72 \mathrm{~kg}$. Berdasarkan data tersebut dapat disimpulkan bahwa harga cabai merah keriting lebih rendah daripada harga cabai rawit dan jumlah cabai merah keriting lebih besar dibandingkan jumlah cabai rawit.

\section{Pengaruh Permintaan Konsumen $\left(\mathbf{X}_{3}\right)$ Terhadap Harga Cabai Rawit (Y)}

Pada Tabel 9. diperoleh $\mathrm{t}_{\text {hitung }} 0,45<2,04 \mathrm{t}_{\text {tabel }}$, yang berarti variabel permintaan konsumen $\left(\mathrm{X}_{3}\right)$ tidak berpengaruh nyata terhadap harga cabai rawit (Y). Hal ini tidak sejalan dengan pendapat Sukirno (2005) yang menyatakan makin rendah harga suatu barang maka makin banyak permintaan terhadap barang tersebut, sebaliknya makin tinggi harga suatu barang maka makin sedikit permintaan terhadap barang tersebut.

Berdasarkan hasil analisis data pada Tabel 9. walaupun harga cabai rawit rendah tidak menunjukkan semakin banyaknya permintaan konsumen dalam membeli cabai rawit atau sebaliknya. Hal ini dikarenakan pedagang cabai rawit di Pasar Ngablak lebih banyak sebagai pedagang pengecer, sehingga cabai rawit yang habis dijual jumlahnya relatif lebih sedikit.

\section{KESIMPULAN DAN SARAN}

\section{Kesimpulan}

Berdasarkan hasil analisis dan pembahasan maka dapat dirumuskan kesimpulan penelitian sebagai berikut:

1. Secara bersama-sama variabel saluran distribusi, harga cabai merah keriting dan permintaan konsumen terhadap cabai rawit berpengaruhnyata terhadap harga cabai rawit.

2. Secara parsial variabel saluran distribusi dan harga cabai merah keriting berpengaruh positif terhadap harga cabai rawit, sedangkan permintaan konsumen terhadap cabai rawit tidak berpengaruh nyata terhadap harga cabai rawit. 
Fina, Yuliawati: Faktor-Faktor yang Mempengaruhi Harga Cabai Rawit ...

Saran

Pemerintah sebaiknya dapat memberikan kebijakan mengenai penetapan harga jual yang stabil, baik dikalangan petani maupun pedagang.

\section{DAFTAR PUSTAKA}

BPS. 2015. Statistik Harga Produsen Pertanian Subsektor Tanaman Pangan, Hortikultura dan Tanaman Perkebunan Rakyat. Jakarta: Badan Pusat Statistik.

BPS Kabupaten Magelang. 2016. Jumlah Penduduk Kabupaten Magelang menurut Jenis Kelamin dan Kecamatan, 2015. Magelang: Badan Pusat Statistik.

Dewi, T. R. 2009. Analisis Permintaan Cabai Merah (Capsicum Annum L) di Kota Surakarta. Skripsi. Universitas Sebelas Maret. Surakarta:

Direktorat Jendral Hortikultura. (2016/04/12). Kementerian Pertanian Informasi Harga Komoditas Pertanian Kabupaten.
Retrieved from https://aplikasi.pertanian.go.id/ smshargakab/qrylaprmsayuprov.asp.

Irawan, B. 2007. Fluktuasi Harga, Transmisi Harga dan Marjin Pemasaran Sayur dan Buah. Jurnal Analisis Kebijakan Pertanian, 5(4), 358-373.

Palar, N., Pangemanan, P.A. dan Tangkere, E.G. 2016. Faktor-Faktor Yang Mempengaruhi Harga Cabai Rawit di Kota Manado. Jurnal Agri-sosioekonomi, 12(2), 105-120.

Prastowo, N.J., Tri Y. dan Yoni D. 2011. Pengaruh Distribusi dalam Pembentukan Harga Komoditas dan Implikasinya terhadap Inflasi. Jakarta: Bank Indonesia.

Sudarsono, 1985. Pengantar Ekonomi Mikro. Jakarta: LP3ES.

Sukirno, S. 2005. Pengantar Mikroekonomi. Edisi Ketiga. Jakarta: Raja Grafindo Persada. 